sibs have multiple polyposis of the colon proved at surgery or necropsy. The eldest was the subject of a case report by Carlson and Novacovich ( $J$ Int Coll Surg 1952; XVIII: 534-40). The father of these sibs died at the age of 70 of cancer of the lung, and had no near relatives with GI cancer. The mother died at the age of $\mathbf{4 2}$ of an annular constricting carcinoma of the splenic flexure with metastases to the liver. She had had a purulent peritonitis, and the mucosa of the ileum, ascending and transverse colon showed numerous small ulcerations, 1 to $7 \mathrm{~mm}$ in diameter. The descending colon showed one small pedunculated polyp. This woman's mother (IT) died of 'cancer of the rectum' at the age of 45, and was thought by the family to have had multiple polyposis.

It seems very likely that IT carried the multiple polyposis gene even though she did not have multiple polyps, and at the time I looked, unsuccessfully, for evidence that the polyps might disappear once a malignancy had developed. However Professor Lynch's paper supports the idea that the correct interpretation was variable expressivity of the gene for multiple polyposis.

F Clarke Fraser Department of Medical Genetics, Montreal Children's Hospital, Montreal, Canada H3H IP3

\section{Prenatal study of X-linked aqueductal stenosis}

SIR,

$\mathrm{X}$ linked aqueductal stenosis (XAS) is an uncommon but well recognised heritable form of hydrocephalus. ${ }^{12}$ The underlying defect is not known. We report the use of ultrasound in the middle trimester of a pregnancy at risk for XAS.

The proband was a woman whose brother had died in the neonatal period of hydrocephalus, as had her sister's son. Necropsies had not been done and a diagnosis of XAS was not certain, but she knew there was a risk of hydrocephalus in male offspring.

Ultrasound examination of the fetus at 17 and 24 weeks' gestation showed biparietal diameters of $3 \cdot 8$ and $5.9 \mathrm{~cm}$, respectively. These values could not be distinguished from controls. An $x$-ray of the pelvis at 36 weeks' gestation showed a large fetal head, and a hydrocephalic male infant was delivered by $\stackrel{\mathbb{Q}}{\rightarrow}$ caesarian section. A CAT scan showed stenosis of the aqueduct of Sylvius and confirmed the existence of XAS in this family.

Enlargement of the fetal head in XAS has been 흘 noted by $x$-ray at 32 weeks' gestation as reported by $\frac{\bar{c}}{\frac{1}{\sigma}}$ Cassie and Boon. ${ }^{3}$ Ultrasound examination in the $\stackrel{\mathbb{Q}}{2}$ middle trimester did not show the presence of hydro- क cephalus in the pregnancy of our patient before 24 weeks : enlargement of the fetal head occurred in the last trimester. The physician should not rely on $\overrightarrow{\vec{\omega}}$ ultrasound in the middle trimester for the prenatal diagnosis of XAS in a pregnancy at risk.

Paul Benke and Richard Strassberg Departments of Pediatrics and Obstetrics, University of Miami School of Medicine, Miami, Florida 33152, USA

\section{References}

1 Bickers DS, Adams RD. Hereditary stenosis of the aqueduct of Sylvius as a cause of congenital hydrocephalus. Brain 1949;72:246-62.

2 Shannon MW, Nadler HL. X-linked hydrocephalus. J Med Genet 1968;5:326-8.

3 Cassie R, Boon AR. Sex linked hydrocephalus. J Med Genet 1977;14:72-3.

\section{John Fraser Roberts's 80th birthday}

SIR,

Will you kindly allow me to use your columns for a happy report, an occasion near to the hearts of $\overrightarrow{\overrightarrow{0}}$ all clinical geneticists, indeed of all who are involved in the different aspects of genetic advice. John Fraser Roberts was born on 8 September 1899. He started the first genetic advice clinic in this country at the Hospital for Sick Children, Great Ormond Street in 1946, and this has grown from strength to strength.

For his work and for his leadership in medical genetics and genetic counselling we are deeply grateful. May we say how delighted we are at the $\stackrel{5}{5}$ continued happiness he derives from his work, and $\frac{D}{O}$ may we extend to him our warmest wishes on this happy occasion?

Paul E Polani and Colleagues N Paediatric Research Unit, N Guy's Hospital, London SE1 9RT. 